\title{
Preparation of Novel Cystine-multiwalled Carbon Nanotubes-graphene Oxide-glassy Carbon Electrode and Electrochemical Detection of Riboflavin and Dopamine
}

\author{
Jun-li Zhang ${ }^{*}$ and Ning Zhang \\ College of Chemical and Pharmaceutical Engineering, Huanghuai University, Zhumadian 463000, China
}

(Received April 27, 2018; accepted August 2, 2018)

Keywords: cystine, graphene oxide, Cys-MWNT-GO-GCE electrode, riboflavin, dopamine

A glassy carbon electrode (GCE) was used as a substrate, and cystine (Cys), carboxylated multiwalled carbon nanotubes (MWNTs), and graphene oxide (GO) were ultrasonically mixed. The surface of the GCE was modified, and a Cys-MWNTs-GO-GCE-modified electrode was prepared. Scanning electron microscopy was conducted to characterize the surface morphology of Cys-MWNTs-GO, which had a loose and porous structure. The electrochemical properties of the modified electrode were examined using $\mathrm{K}_{3}\left[\mathrm{Fe}(\mathrm{CN})_{6}\right]$, and the calculated electrode area of Cys-MWNTs-GO-GCE was $7.0397 \times 10^{-6} \mathrm{~cm}^{2}$. Results also showed that the maximum amperometric response of the modified electrode was reached when the $\mathrm{pH}$ values of phosphatebuffered saline for vitamin $\mathrm{B}_{2}\left(\mathrm{VB}_{2}\right)$ and dopamine (DA) were 6.60 and 7.00, respectively. The modified electrode could detect $\mathrm{VB}_{2}$ and $\mathrm{DA}$ in the linear concentration ranges of $2.0 \times 10^{-9}$ $3.0 \times 10^{-4}$ and $1.3 \times 10^{-8}-2.5 \times 10^{-4} \mathrm{~mol} / \mathrm{L}$, respectively. Linear equations could be described as follows: $I_{\mathrm{p}(\mathrm{VB} 2)}=4.6149+4.9889 \mathrm{c}$ and $I_{\mathrm{p}(\mathrm{DA})}=3.0063+1.8508 \mathrm{c}$. The detection limits of $\mathrm{VB}_{2}$ and $\mathrm{DA}$ were $1.2 \times 10^{-9}$ and $1.0 \times 10^{-9} \mathrm{~mol} / \mathrm{L}$, respectively $(S / N=3)$. These results demonstrated the high stability and reproducibility of the detection method with a peak current of $\operatorname{RSD}=1.37 \%$. The developed method could be applied to determine the contents of $\mathrm{VB}_{2}$ and DA in urine and blood samples, respectively.

\section{Introduction}

Vitamin $\mathrm{B}_{2}\left(\mathrm{VB}_{2}\right)$, also known as riboflavin, is an important component of flavin mononucleic acid (FMN) and flavin adenine dinucleotide (FAD). FMN and FAD not only serve as important coenzymes in the body but also participate in the catalysis of biological redox reactions. Thus, they are involved in many important metabolic activities in organisms. $\mathrm{VB}_{2}$ is commonly used in various fields, such as food, medicine, and biochemistry. Therefore, the efficient and sensitive detection of riboflavin in vivo is a key step to preventing diseases. ${ }^{(1,2)}$ Dopamine (DA) is an important neurotransmitter in the nervous systems of humans and other mammals. ${ }^{(3)}$ It is used to treat Parkinson's disease and other typical neurological diseases.

*Corresponding author: e-mail: zjlwzq529@sina.com https://doi.org/10.18494/SAM.2018.1970 
Many methods of determining $\mathrm{VB}_{2}$ and $\mathrm{DA}$ have been reported. However, these methods, including ion chromatography and fluorescence, are limited by poor sensitivity and stability, duration, ion interference, toxicity, secondary pollution, and complex or time-consuming measurements. By contrast, electrochemical methods have advantages, such as low cost, simple operation, low detection limits, high sensitivity, and extensive application range. ${ }^{(4-14)}$ Because through immobilizing ions, molecules, and polymers to bare electrode surfaces to form a microstructure, therefore chemically modified electrodes have special electrochemical properties and advantages, including good selectivity and high sensitivity. ${ }^{(15-17)}$ Carboxylated multiwalled carbon nanotubes (MWNTs) also have a unique structure and special electrical and mechanical properties. A new composite electrode material has been prepared by adding MWNTs into a polymer. They also have a superior ability to promote electron transfer reactions because electrode materials can accelerate electron exchange and improve signal strength. ${ }^{(18-21)}$ Graphene oxide (GO) is a new type of two-dimensional (2D) carbon nanomaterial, whose surface contains a large amount of carboxyl, hydroxyl, and epoxy groups, such as oxygencontaining groups, with good water solubility and stability. ${ }^{(22,23)}$ Cystine (Cys), also known as L-cystine, is a sulfur-containing amino acid obtained through the oxidation of two cysteine molecules. An electrode surface, which is used to modify electrodes, can be introduced to the amino, carboxyl, and other reactive groups of Cys and combined with the hydroxyl group of other substances to form hydrogen bonds and other intermolecular interactions. ${ }^{(24)}$ $\mathrm{Yu}$ et al. developed a sensitive amperometric biosensing system for riboflavin detection by integrating a whole-cell redox cycling system with a conventional riboflavin electrochemical sensor. $^{(12)}$ Khan et al. investigated 2D crystalline hexagonal boron nitride nanosheets as potential electrocatalysts for the electroanalytical sensing of DA. ${ }^{(14)}$ Zhang et al. prepared a novel RGO/A32/Au electrochemical sensor to detect riboflavin, and its cathodic peak current increases linearly when the concentration of riboflavin increases from 0.025 to $2.75 \mu \mathrm{mol} / \mathrm{L}$ with a low detection limit of $15 \mathrm{nmol} / \mathrm{L} .{ }^{(23)}$ Wu et al. prepared a GO-glassy carbon electrode (GCE), and DPV peak currents are linear with the concentrations of DA at 1.0-98.0 $\mu \mathrm{mol} / \mathrm{L}$, and the detection limit is $1.0 \mu \mathrm{mol} / \mathrm{L} .^{(25)}$

In this study, a GCE was used as a substrate, and Cys, MWNTs, and GO were ultrasonically mixed, and then the mixture was dripped onto the GCE electrode. Thus, a novel Cys-MWNTsGO-GCE-modified electrode was prepared. Hydrogen bonds and van der Waals forces were formed among the amino group of Cys, the hydroxyl group on the GO surface, and the carboxyl group of MWNTs. This simple and controllable operation was also used to investigate the electrochemical responses of DA and riboflavin through cyclic voltammetry (CV). To the best of our knowledge, this technology is uncommon and less reported. This method has various advantages, such as simple preparation, low cost, high sensitivity and stability, and fast and convenient operation. For these reasons, Cys-MWNTs-GO-GCE-modified electrodes show potential for the high-sensitivity electrochemical detection of DA and riboflavin.

\section{Experimental Procedure}

\subsection{Materials and equipment}

CV measurements were performed in a Zennium electrochemical workstation (Zahner, Germany). A UV-visible spectrophotometer Cary100 (Agilent, USA) and a JSM-5600 
scanning electron microscope (Japan Electronics Co., Ltd.) were used. Cys was obtained from Shanghai Blue Seasons Technology Development Co., Ltd. Riboflavin (Biochemical Reagents) was obtained from Sinopharm Chemical Reagent Co., Ltd. DA (Biochemical Reagents) and carboxylated MWNTs $(d \leq 50 \mathrm{~nm})$ were purchased from Sinopharm Chemical Reagent Co., Ltd. and Chengdu Institute of Organic Chemistry, respectively. Analytical-grade GO was obtained from Shanxi Institute of Coal Chemistry, Chinese Academy of Sciences. Deionized water was used throughout the experiment.

\subsection{Methods}

A GCE was polished with $\mathrm{Al}_{2} \mathrm{O}_{3}$ powder, cleaned, and placed in an ultrasonic bath for 6 min initially in a 1:1 solution of nitric acid and ethanol and then in deionized water. Cys $(0.02 \mathrm{~g})$ and MWNTs $(0.005 \mathrm{~g})$ were added to a GO solution $(5 \mathrm{~mL})$. After oscillating to disperse GO and MWNTs, the resulting black suspension $(5 \mu \mathrm{L})$ was applied to the GCE. The mixed droplets were applied to the GCE surface and dried under infrared light to prepare a Cys-MWNTs-GOGCE-modified electrode.

We used a three-electrode system composed of a platinum electrode as a counter (auxiliary) electrode (CE), a saturated calomel electrode as a reference electrode (RE), and Cys-MWNTsGO-GCE as a working electrode (WE).

\section{Results and Discussion}

\subsection{SEM images of GO, MWNTs, and Cys-MWNTs-GO}

Figures 1(a) and 1(b) show the scanning electron microscopy images of GO and MWNTs, respectively. The SEM image of Cys-MWNTs-GO is shown in Fig. 1(c). In ultrasonic mixing, the MWNTs became dispersed and interpenetrated evenly in the GO. Furthermore, MWNTs stretched the graphene sheets. As a result, the Cys-MWNTs-GO membrane was densely covered and uniformly distributed, thereby maintaining a filmlike stacked porous structure, which facilitated electron transfer.

\subsection{Electrochemical behaviors of $\mathrm{VB}_{2}$ and $\mathrm{K}_{3}\left[\mathrm{Fe}(\mathrm{CN})_{6}\right]$ on different electrodes}

With pH $6.60 \mathrm{PBS}$ buffer solutions, $\mathrm{VB}_{2}$ was measured at a scanning speed of $100 \mathrm{mV} / \mathrm{s}$. At the GCE [Fig. 2(A), curve b], the oxidation and reduction peak currents of $\mathrm{VB}_{2}$ were small. $A$ distinct pair of redox peaks of $\mathrm{VB}_{2}$ could be detected in the Cys-MWNTs-GCE [Fig. 2(A), curve c]. Simultaneously, the peak current increased, the $\mathrm{VB}_{2}$ oxidation peak negatively shifted to $-0.464 \mathrm{~V}$, and the reduction peak potential decreased to $-0.506 \mathrm{~V}$. In the Cys-MWNTsGO-GCE [Fig. 2(A), curve d], the peak current increased significantly and the redox peaks were almost completely symmetrical. The peak current ratio was approximately 1:1, indicating that the electrochemical reaction of $\mathrm{VB}_{2}$ is a quasi-reversible process. The oxidation peak of $\mathrm{VB}_{2}$ negatively shifted to $-0.478 \mathrm{~V}$, whereas the reduction peak potential reached -0.502 $\mathrm{V}$. The potential difference was significantly reduced. These results might be attributed to a redox reaction that reduced GO to graphene during the electrochemical reaction. Graphene 


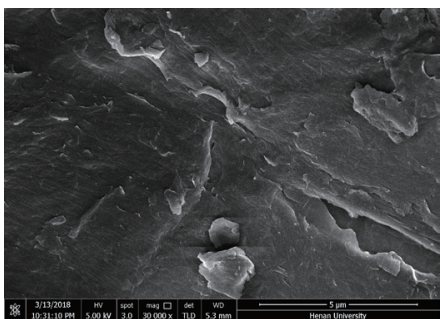

(a)

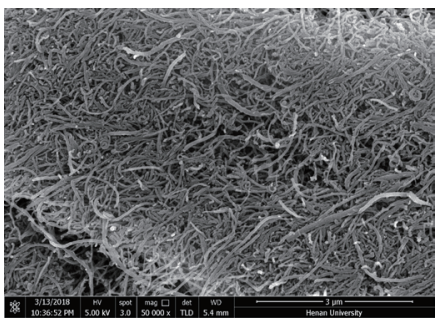

(b)

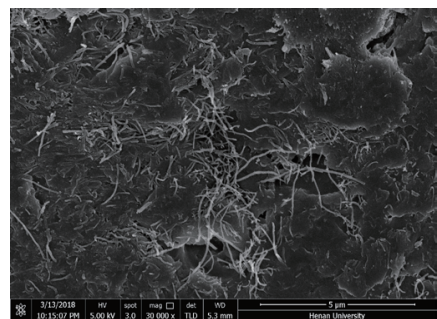

(c)

Fig. 1. SEM images of (a) GO, (b) MWNTs, and (c) Cys-MWNTs-GO.

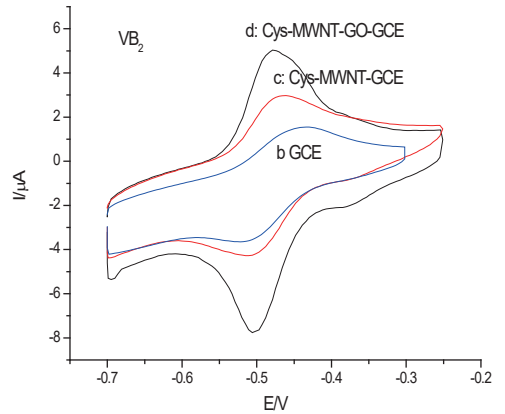

(A)

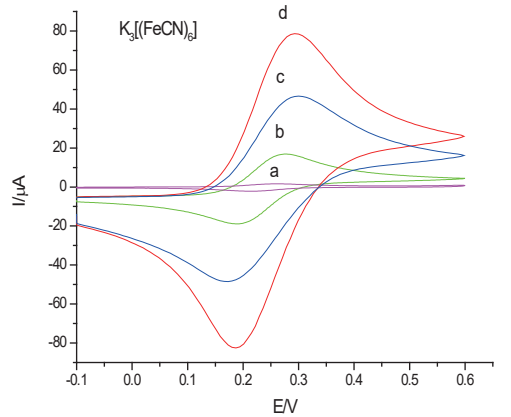

(B)

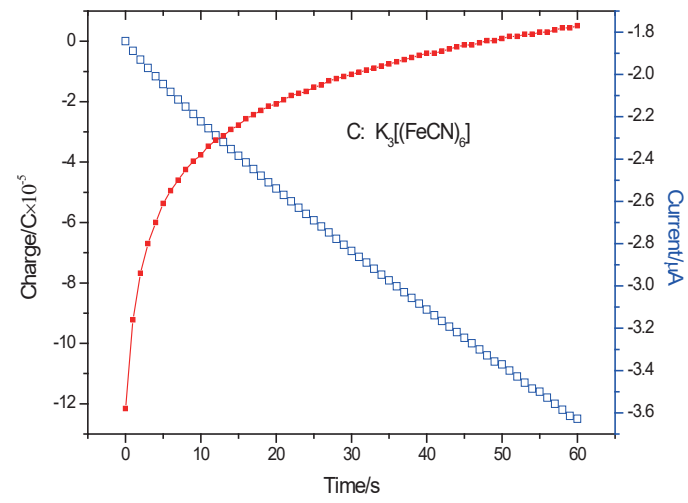

(C)

Fig. 2. (Color online) Cyclic voltammograms of (A) $\mathrm{VB}_{2}$ and (B) $\mathrm{K}_{3}\left[(\mathrm{FeCN})_{6}\right]$ on (a) GO-GCE, (b) GCE, (c) CysMWNTS-GCE, and (d) Cys-MWNTs-GO-GCE. (C) $\mathrm{VB}_{2}: 1.0 \times 10^{-6} \mathrm{~mol} / \mathrm{L} ; \mathrm{K}_{3}\left[(\mathrm{FeCN})_{6}\right]: 0.05 \mathrm{~mol} / \mathrm{L}$; scanning rate of $100 \mathrm{mV} / \mathrm{s}$; chrono coulometry of $\mathrm{K}_{3}\left[(\mathrm{FeCN})_{6}\right], 0.2 \mathrm{~mol} / \mathrm{L}$.

accelerates electron transfer, resulting in an increased peak current. ${ }^{(1)}$ Carbon nanotubes on the surface of the modified electrode greatly facilitated the migration of electrons. MWNTs have a special electronic structure, conductivity, and smaller geometry. The amino group of Cys, the hydroxyl group of the GO surface, and the carboxyl group of MWNTs induced the formation of 
hydrogen bonds and van der Waals forces, and other interactions through a chemical reaction. These three substances create a good combination. ${ }^{(24)}$ As a result, the effective reaction area of the electrode increased to form a three-dimensional porous network structure, and more reaction sites were provided for electrocatalytic oxidation, which accelerated electron transfer, played a synergistic role, and improved the catalytic performance. The results showed that Cys, GO, and MWNTs were successfully modified to a GCE surface.

Phosphate-buffered saline (PBS) was used as the bottom liquid, and $\mathrm{K}_{3}\left[\mathrm{Fe}(\mathrm{CN})_{6}\right](0.05 \mathrm{~mol} / \mathrm{L})$ was utilized as a probe to test the sensor properties of (a) GO-GCE, (b) GCE, (c) Cys-MWNTsGCE, and (d) Cys-MWNTs-GO-GCE [Fig. 2(B)]. The electrochemical response of $\mathrm{K}_{3}\left[\mathrm{Fe}(\mathrm{CN})_{6}\right]$ was weak when the GCE was modified with $\mathrm{GO}$ alone. The peak current of $\mathrm{K}_{3}\left[\mathrm{Fe}(\mathrm{CN})_{6}\right]$ was higher when the Cys-MWNTs-GO-GCE was applied. The composite membrane has a strong enrichment ability and synergistic catalytic performance. As such, it was beneficial to the redox reaction of more active substances, thereby enhancing the voltammetric response. For reversible processes, the Randles-Sevcik equation was used.

$$
i_{p}=2.69 \times 10^{5} n^{2 / 3} A D^{1 / 2} v^{1 / 2} c
$$

The effective areas of the GCE and Cys-MWNTs-GO-GCE were $1.5791 \times 10^{-6}$ and $7.0397 \times 10^{-6}$ $\mathrm{cm}^{2}$, respectively, indicating that the surface area of the effective composite nanofilm formed with the modified electrode increased nearly five times. The addition of GO and MWNTs also promoted the formation of a network-meshed structure, thereby allowing more active substances to be adsorbed and enriching the electrode surface. When the electrode surface had a highly uniform dispersion of MWNTs and electroreduced $\mathrm{GO}, \mathrm{K}_{3}\left[\mathrm{Fe}(\mathrm{CN})_{6}\right]$ exhibited a strong electrocatalytic oxidation, and the electron transfer significantly accelerated. This result also demonstrated that MWNTs contributed to the acceleration of the electron transfer of $\mathrm{Fe}^{2+}$ to $\mathrm{Fe}^{3+}$ by graphene, thereby promoting the electrochemical reaction of the measured material.

The modified electrode was used for the chronoelectric analysis in a mixed solution of 1.0 $\times 10^{-2} \mathrm{~mol} / \mathrm{L}$ potassium ferricyanide and $0.1 \mathrm{~mol} / \mathrm{L}$ potassium nitrate. The point was evenly taken from the chronoelectricity curve, and the following equation was obtained: $Q=6.5432 \times$ $10^{-6}-2.446 \times 10^{-5} t^{1 / 2}, R=0.9988$. Thus, $Q=2 n F A C_{0} D^{1 / 2} t^{1 / 2} / \pi^{1 / 2}+Q_{a d s}+Q_{d l}$, and the effective electrode area $A$ can be calculated as $2.13 \times 10^{-4} \mathrm{~cm}^{2}$. The effective electrode area involves not only the surface area but also the catalytic current coming from active sites, thereby providing different amounts and activities of active sites by MWNTs and GO.

\subsection{Effect of $\mathbf{p H}$}

In Fig. 3, the $\mathrm{VB}_{2}$ contents of PBS buffer solutions containing $\mathrm{VB}_{2}\left(1.0 \times 10^{-6} \mathrm{~mol} / \mathrm{L}\right)$ and at $\mathrm{pH}=6.0,6.2,6.4,6.6,6.8,7.0$, and 7.4 were verified using Cys-MWNTs-GO-GCE as the WE. The $\mathrm{VB}_{2}$ oxidation peak current reached a maximum at $\mathrm{pH}$ 6.6. Therefore, a buffer solution of pH 6.6 was selected as the supporting electrolyte.

Figure 3 shows the PBS buffer solutions containing DA $\left(6.0 \times 10^{-6} \mathrm{~mol} / \mathrm{L}\right)$ and with $\mathrm{pH}=$ $6.6,6.8,7.0,7.2,7.4,7.6$, and 7.8 at a sweep speed of $100 \mathrm{mV} / \mathrm{s}$. The oxidation peak current of 


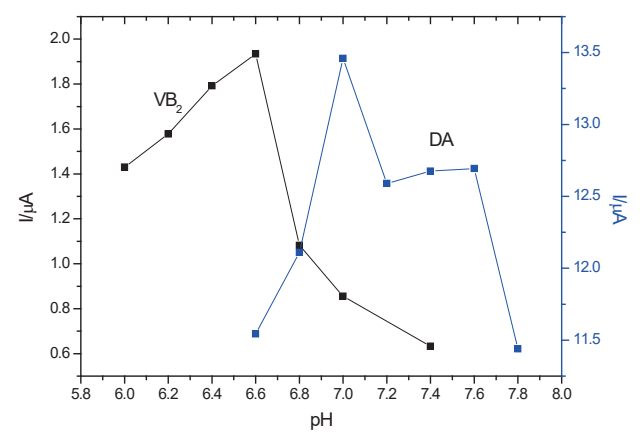

Fig. 3. (Color online) Effects of $\mathrm{pH}$ on oxidation peak current. $\left(\mathrm{VB}_{2}: 1.0 \times 10^{-6} \mathrm{~mol} / \mathrm{L}\right.$, $\mathrm{pH}$ 6.0, 6.2, 6.4, 6.6, 6.8, 7.0, and 7.4) $\left(\mathrm{DA}: 6.0 \times 10^{-6} \mathrm{~mol} / \mathrm{L}, \mathrm{pH} 6.6,6.8,7.0,7.2,7.4,7.6\right.$, and 7.8), $100 \mathrm{mV} / \mathrm{s}$.

DA in the modified electrode initially increased and then decreased as $\mathrm{pH}$ increased. At $\mathrm{pH}$ 7.00 , the oxidation peak current was the strongest possibly because of the deprotonation of DA oxidation. The number of protons and transferred electrons of DA were the same on the CysMWNTs-GO-GCE-modified electrode during the electrochemical reaction, consistent with the literature description. ${ }^{(22)}$ At the same time, the formation of hydrogen bonds between the amino group on Cys with the hydroxyl group on DA also contributed to the enrichment of DA at the modified electrode. With this synergistic effect, the catalytic effect of Cys-MWNTs-GOGCE on DA was enhanced. Therefore, the PBS buffer solution with $\mathrm{pH} 7.0$ was selected for the determination of DA content.

\subsection{Effect of scanning rate}

Figure 4(A) shows the CV curves of $\mathrm{VB}_{2}(0.05 \mathrm{~mol} / \mathrm{L}, \mathrm{pH}$ 6.6) with the Cys-MWNTsGO-GCE. The results showed that the oxidation peak current of $\mathrm{VB}_{2}$ increased as the sweep velocity increased. A positive shift to a high potential began, and the potential shifted to the right from -0.369 to $-0.355 \mathrm{~V}$. The ratio of the oxidation peak to the reduction peak current was approximately 1:1. This result indicated that the reaction with the electrode was reversible. The peak current and scanning rate had a linear relationship:

$$
I_{p(V B 2)}=-0.0632+0.3968 v, R^{2}=0.9991 .
$$

The redox reactions of $\mathrm{VB}_{2}$ were attributed to the adsorption control process. $\lg I_{p}$ and $\lg v$ also demonstrated a linear relationship. The linear equation is expressed as

$$
\lg I_{p(V B 2)}=-0.4328+0.1060 \lg v, R^{2}=0.9990 .
$$

However, the slope is $>1.0$. These findings showed that the electrode process is controlled only by adsorption. This conclusion is different from previous findings, which revealed that the electrode process is controlled by diffusion or adsorption-diffusion mixing. ${ }^{(10,23,27)}$ According to the Laviron formula: $I_{p}=n F Q v / 4 R T$, the number of transferred electrons $n=1.71 \approx 2$ was 


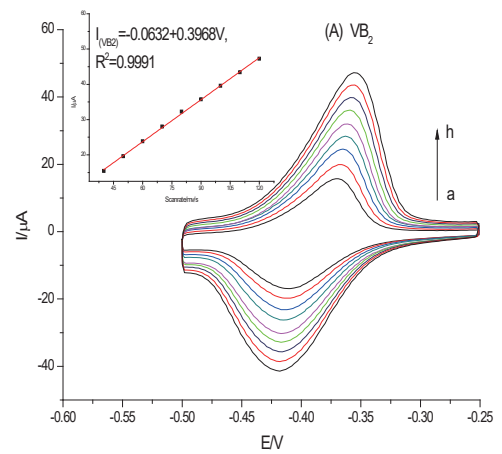

(A)

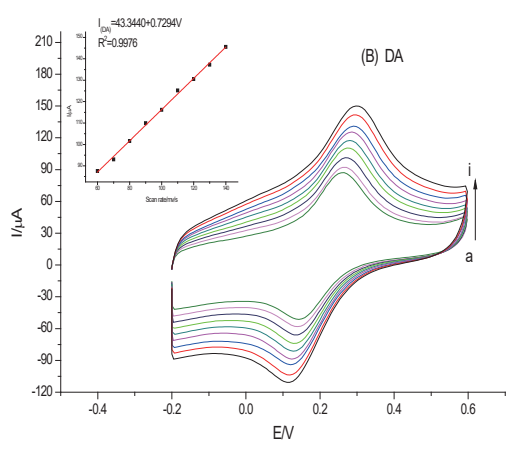

(B)

Fig. 4. (Color online) Cyclic voltammograms of VB2 and DA at different scanning rates. (A) VB2, (a)-(i): 40, 50, $60,70,80,90,100,110$, and $120 \mathrm{mV} / \mathrm{s}, \mathrm{pH} 6.60$ and (B) DA, (a)-(i): 60, 70, 80, 90, 100, 110, 120, 130, and $140 \mathrm{mV} / \mathrm{s}$, $\mathrm{pH} 7.00$.

calculated at $\mathrm{T}=298 \mathrm{~K}$ and $v=100 \mathrm{mV} / \mathrm{s}$. At the same time, data analysis showed that the oxidation peak potential was linearly related to $\mathrm{pH}$, and its linear regression equation was as follows: $E_{p}=-0.961+0.091 \mathrm{pH}$. The correlation coefficient was 0.9943 .

The relationship between the peak potential and the number of protons in the system is shown as

$$
E_{p}=K-0.059(m / n) \mathrm{pH}
$$

where $E_{p}$ is the peak potential, $m$ is the number of protons involved, $n$ is the number of electron transfers, and $K$ is the slope. $m / n$ is approximately equal to 1 based on the slope of the line. This finding showed that the oxidation of $\mathrm{VB}_{2}$ was a double proton double electron electrode reaction. ${ }^{(27)}$

The effect of scanning speed on the oxidation peak current of DA $\left(2.5 \times 10^{-3} \mathrm{~mol} / \mathrm{L}\right)$ was studied using Cys-MWNTs-GO-GCE as the WE in a PBS buffer solution of $\mathrm{pH} 7.0$ and various sweep velocities [Fig. 4(B)]. The oxidation peak potential of DA also positively shifted, and the oxidation peak current increased. In the range of $60-140 \mathrm{mV} / \mathrm{s}$, the oxidation peak current $I_{p}$ was linearly related to the square root of the sweep velocity $v$.

$$
I_{p(D A)}=43.3440+0.7294 v, R^{2}=0.9976
$$

This relationship indicated that the electrochemical oxidation of DA on Cys-MWNTs-GOGCE is controlled by adsorption. ${ }^{(22)}$ The oxidation peak current $I_{p}$ and the square root of $v$ also showed a good linear relationship.

$$
I_{p(D A)}=-25.695+14.3229 v^{1 / 2}, R^{2}=0.9951
$$

This result showed that the electrode underwent controlled diffusion in this $v$ range. ${ }^{(28)} \lg I_{p}$ and $\lg v$ also demonstrated a linear relationship. The linear equation is expressed as

$$
\lg I_{p(D A)}=0.8504+0.6093 \lg v, R=0.9957 .
$$


The slope is between 0.5 and 1.0, showing that the electrode process was controlled by adsorption-diffusion mixing.

\subsection{Working curve and detection limit}

The relationship between the $\mathrm{VB}_{2}$ concentration and the peak current was studied through $\mathrm{CV}$ under the optimized experimental conditions [Fig. 5(A)]. The results showed that the $\mathrm{VB}_{2}$ oxidation peak current increased with concentration. The linear relationship of the oxidation peak current and the $\mathrm{VB}_{2}$ concentration was in the range of $2.0 \times 10^{-9}-3 \times 10^{-4} \mathrm{~mol} / \mathrm{L}$. The linear equation representing the $\mathrm{VB}_{2}$ concentration is

$$
I_{p(V B 2)}=4.6149+4.9889 c, R^{2}=0.9985 .
$$

The detection limit was $(S / N=3) 1.2 \times 10^{-9} \mathrm{~mol} / \mathrm{L}$. These results demonstrated that the modified electrode elicits favorable electric catalytic effects on $\mathrm{VB}_{2}$. Compared with previously reported systems, the electrode presented a wider linear range and a lower detection

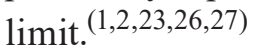

In a PBS solution with $\mathrm{pH}$ 7.0, Cys-MWNTs-GO-GCE was used as the WE to perform CV. In Fig. 5(B), the oxidation peak current was linearly related to the DA concentration in the range of $1.3 \times 10^{-8}-2.5 \times 10^{-4} \mathrm{~mol} / \mathrm{L}$, and the linear equation was

$$
I_{p(D A)}=3.0063+1.8508 c, R^{2}=0.9962 .
$$

The detection limit was $1.0 \times 10^{-9} \mathrm{~mol} / \mathrm{L}(S / N=3)$. The results showed that the sensor had a high sensitivity.

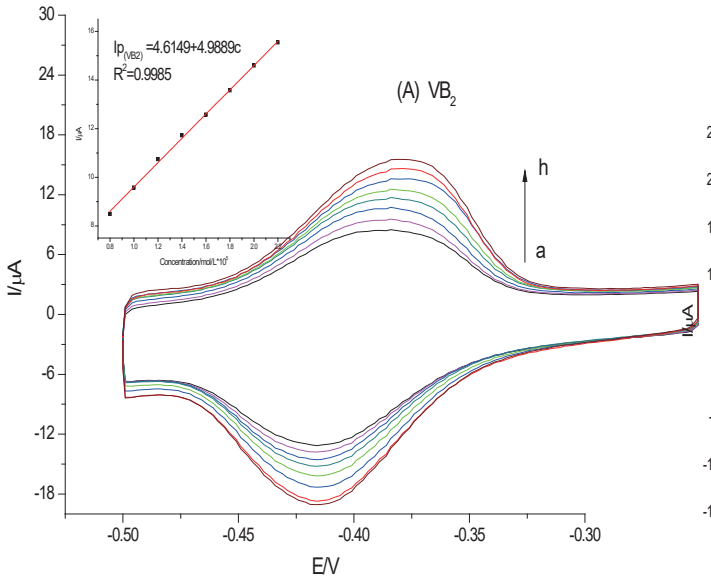

(A)

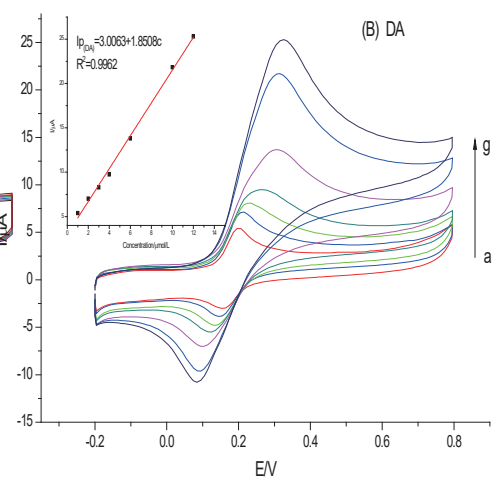

(B)

Fig. 5. (Color online) Cyclic voltammograms of VB2 and DA at various concentrations. (A) $\mathrm{VB}_{2}$ : [(a) $0.8 \times 10^{-5}$; (b) $1.0 \times 10^{-5}$; (c) $1.2 \times 10^{-5}$; (d) $1.4 \times 10^{-5}$; (e) $1.6 \times 10^{-5}$; (f) $1.8 \times 10^{-5}$; (g) $2.0 \times 10^{-5}$; (h) $2.2 \times 10^{-5} \mathrm{~mol} / \mathrm{L}$; pH 6.60 , scan rate $=0.1 \mathrm{~V} / \mathrm{s}$ ] (B) DA: [(a) $1.0 \times 10^{-6}$; (b) $2.0 \times 10^{-6}$; (c) $3.0 \times 10^{-6}$; (d) $4.0 \times 10^{-6}$; (e) $6.0 \times 10^{-6}$; (f) $10.0 \times 10^{-6}$; (g) $12.0 \times 10^{-6} \mathrm{~mol} / \mathrm{L} ; \mathrm{pH} 7.00$, scan rate $\left.=0.1 \mathrm{~V} / \mathrm{s}\right]$. 
The performance of Cys-MWNTs-GO-GCE was compared with those of other modified electrodes used for the previous determination of DA. The results showed that the sensitivity of Cys-MWNTs-GO-GCE was higher than those of other modified electrodes, and the detection limit of the former was lower than that of the latter (Table 1). ${ }^{(22,25,28-30)}$

\subsection{Reproducibility, stability, and interference experiments}

The DA solution $\left(4.0 \times 10^{-6} \mathrm{~mol} / \mathrm{L}\right)$ was scanned 10 times through $\mathrm{CV}$ by using CysMWNTs-GO-GCE. The relative standard deviation was 1.37\%. Eight Cys-MWNTs-GOGCEs were prepared in the same manner. The relative standard deviations of the $\mathrm{VB}_{2}$ and $\mathrm{DA}$ peak currents were 1.5 and $1.9 \%$, respectively. The modified electrode was stored at $4{ }^{\circ} \mathrm{C}$ for 1 week, and the DA response signal was maintained above $95 \%$. These results demonstrated the high reproducibility and stability of the prepared electrode.

The anti-interference ability of Cys-MWNTs-GO-GCE was investigated within the limit of less than 5\% relative error signal. The results showed that adding interfering substances, such as citric acid, vitamin $\mathrm{C}$, uric acid, and glucose, to DA solution had no significant effect on the determination of DA. No interference by vitamin $B_{1}$, vitamin $B_{6}$, nicotinamide, niacin, vitamin $C$, uric acid, tryptophan, and DA on riboflavin detection was observed.

\subsection{Sample detection}

Cys-MWNTs-GO-GCE was used to determine riboflavin in human urine. A human urine specimen was centrifuged at $1000 \mathrm{rpm}$ for $30 \mathrm{~min}$. The supernatant was obtained and filtered through a microporous membrane. Riboflavin in urine $(5 \mathrm{~mL})$, which was concentrated 10 times and then added with $5 \mathrm{~mL}$ PBS buffer solution $(\mathrm{pH}=6.6)$, was determined by this method, and the result revealed a low content of riboflavin $(4.36 \mu \mathrm{mol} / \mathrm{L})$. Different concentrations of riboflavin standard were added to this human urine. The reliability of the method was evaluated

Table 1

Comparison of the linear ranges and detection limits of $\mathrm{VB}_{2}$ and $\mathrm{DA}$ using the present technique with reported methods.

\begin{tabular}{|c|c|c|c|c|c|}
\hline \multirow{2}{*}{ Electrode } & \multicolumn{2}{|c|}{ Linear range $(\mathrm{mol} / \mathrm{L})$} & \multicolumn{2}{|c|}{ Detection limit (mol/L) } & \multirow{2}{*}{ Reference } \\
\hline & $\mathrm{VB}_{2}$ & DA & $\mathrm{VB}_{2}$ & DA & \\
\hline Cys-MWNTS-GO-GCE & $2.0 \times 10^{-9}-3 \times 10^{-4}$ & $1.3 \times 10^{-8}-2.5 \times 10^{-4}$ & $1.3 \times 10^{-9}$ & $1.0 \times 10^{-9}$ & $\begin{array}{c}\text { Presented } \\
\text { method }\end{array}$ \\
\hline PW /PAP & $2.4 \times 10^{-6}-1.0 \times 10^{-4}$ & & $1.4 \times 10^{-6}$ & & (2) \\
\hline $\mathrm{ARS} / \mathrm{CPE}$ & $1.0 \times 10^{-6}-8.0 \times 10^{-4}$ & & $2.5 \times 10^{-8}$ & & $(27)$ \\
\hline $\mathrm{RGO} / \mathrm{A}_{32} / \mathrm{Au}$ & $0.025 \times 10^{-6}-2.75 \times 10^{-6}$ & & $15 \times 10^{-9}$ & & (23) \\
\hline ECGO/Nafion & $7.5 \times 10^{-8}-1.0 \times 10^{-5}$ & & $2.5 \times 10^{-8}$ & & (1) \\
\hline Au-PDA-MWCNTs/GCE & $5.0 \times 10^{-9}-1.0 \times 10^{-5}$ & & $1.7 \times 10^{-9}$ & & (26) \\
\hline $\mathrm{PBPB} / \mathrm{GO} / \mathrm{GCE}$ & & $5.0 \times 10^{-8}-2.0 \times 10^{-4}$ & & $1.0 \times 10^{-8}$ & $(22)$ \\
\hline $\mathrm{GO} / \mathrm{GCE}$ & & $1.0 \times 10^{-6}-98 \times 10^{-6}$ & & $0.5 \times 10^{-6}$ & $(25)$ \\
\hline $\mathrm{Au}-\mathrm{PLC} / \mathrm{GCE}$ & & $2.0 \times 10^{-6}-3.0 \times 10^{-4}$ & & $2.08 \times 10^{-7}$ & $(28)$ \\
\hline poly-(MA)-ERGO/GCE & & $1.0 \times 10^{-8}-5.0 \times 10^{-6}$ & & $5.0 \times 10^{-9}$ & (29) \\
\hline Au-Graphene/GCE & & $1.996 \times 10^{-6}-5.478 \times 10^{-3}$ & & $1.03 \times 10^{-7}$ & (30) \\
\hline
\end{tabular}


using Cys-MWNTs-GO-GCE under optimized experimental conditions. The experimental results are listed in Table 2 . The $\mathrm{VB}_{2}$ aqueous solution has directly absorption in the ultraviolet region. After preparing a series of $\mathrm{VB}_{2}$ standard solutions $(0.11,1.1,1.65,22.0,27.5,33.0$, and $38.5 \mu \mathrm{mol} / \mathrm{L}$ ), a standard curve was made. Using a $1 \mathrm{~cm}$ cuvette, riboflavin in urine (concentrated 10 times) was detected by UV-visible spectrophotometry [maximum absorption wavelength of $265 \mathrm{~nm}$ (Fig. 6)]. The results revealed that the obtained value was $4.30 \mu \mathrm{mol} / \mathrm{L}$, similar to those determined through electrochemical measurements.

DA in human serum samples ( $5 \mathrm{~mL}$, Second Chinese Medicine Hospital of Zhumadian City) was determined using Cys-MWNTs-GO-GCE through 5-fold dilution with PBS buffer ( $\mathrm{pH}$ 7.0). The finding was $3.15 \mu \mathrm{mol} / \mathrm{L}$. The recovery of the results is shown in Table 2. DA and sodium nitrite can produce higher absorbance products in aqueous media. Therefore, the DA content was determined by ultraviolet-visible spectrophotometry. $5 \mathrm{~mL}$ each of the 19.6, 39.2, $58.8,78.4,98.0$, and $117.6 \mu \mathrm{mol} / \mathrm{L}$ DA standard solutions, and $5 \mathrm{~mL}$ of the serum sample were accurately measured and then transferred to 7 colorimetric tubes $(50 \mathrm{~mL}) .5 \mathrm{~mL}$ of $\mathrm{NaNO}_{2}(10$ $\mathrm{mg} / \mathrm{mL})$ solution and $15 \mathrm{~mL}$ of HAc-NaAc buffer solution $(\mathrm{pH}=5.9)$ were added separately. Subsequently, the samples were then shaken well, heated for $3.5 \mathrm{~min}$ in a boiling water bath, removed and cooled to room temperature with running water, and again shaken well. With reference to reagent blank, using a $1 \mathrm{~cm}$ cuvette, according to the maximum absorbance of DA and sodium nitrite at a wavelength of $304 \mathrm{~nm}$, DA was determined. After making a standard curve, the finding was $3.11 \mu \mathrm{mol} / \mathrm{L}$, and the obtained results of the modified electrode were similar. This method could satisfy the requirements of analysis.

Table 2

Results of detecting $\mathrm{VB}_{2}$ in urine samples and DA in human blood $(n=3)$.

\begin{tabular}{ccccccccccc}
\hline \multirow{2}{*}{ Sample } & \multicolumn{2}{c}{$\begin{array}{c}\text { Found } \\
(\mu \mathrm{mol} / \mathrm{L})\end{array}$} & \multicolumn{2}{c}{$\begin{array}{c}\text { Added } \\
(\mu \mathrm{mol} / \mathrm{L})\end{array}$} & \multicolumn{2}{c}{$\begin{array}{c}\text { Total found } \\
(\mu \mathrm{mol} / \mathrm{L})\end{array}$} & \multicolumn{2}{c}{$\begin{array}{c}\text { RSD } \\
(\%, n=3)\end{array}$} & \multicolumn{2}{c}{$\begin{array}{c}\text { Recovery } \\
(\%)\end{array}$} \\
\cline { 2 - 12 } & $\mathrm{VB}_{2}$ & $\mathrm{DA}$ & $\mathrm{VB}_{2}$ & $\mathrm{DA}$ & $\mathrm{VB}_{2}$ & $\mathrm{DA}$ & $\mathrm{VB}_{2}$ & $\mathrm{DA}$ & $\mathrm{VB}_{2}$ & $\mathrm{DA}$ \\
\hline 1 & 4.36 & 3.15 & 1 & 1 & 5.31 & 4.16 & 2.1 & 1.2 & 95 & 101 \\
2 & 4.36 & 3.15 & 2 & 2 & 6.37 & 5.11 & 1.1 & 1.5 & 100.5 & 98 \\
3 & 4.36 & 3.15 & 3 & 3 & 7.35 & 6.11 & 0.9 & 1.3 & 99.7 & 98.7 \\
\hline
\end{tabular}

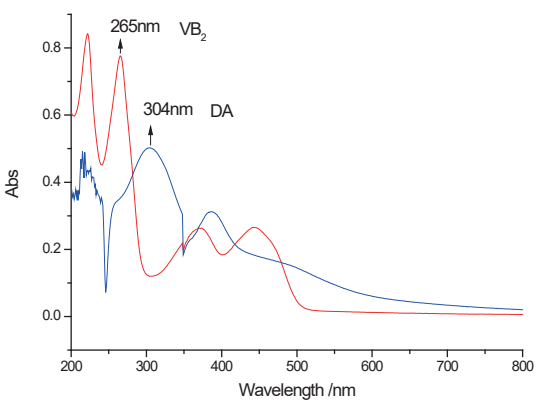

Fig. 6. (Color online) UV spectra of $\mathrm{VB}_{2}\left(3.3 \times 10^{-5} \mathrm{~mol} / \mathrm{L}\right)$ and $\mathrm{DA}\left(3.92 \times 10^{-6} \mathrm{~mol} / \mathrm{L}\right)$. 


\section{Conclusions}

(1) Scanning electron microscopy was conducted to characterize the surface morphology of Cys-MWNTs-GO. The electrochemical behavior of riboflavin and DA was examined. The redox electrochemical reaction of $\mathrm{VB}_{2}$ was controlled by adsorption, but DA was simultaneously controlled by adsorption and diffusion.

(2) The modified electrode exhibited excellent electrochemical properties, such as high sensitivity, good reproducibility and stability, and low detection limit. In the actual sample analysis, the results were similar to those obtained through conventional methods. The proposed method showed potential for the detection of riboflavin and DA.

\section{Acknowledgments}

This study was financially supported by the National Natural Science Foundation of China (Grant No. U1204210), the Science and Technology Projects of Henan Province (Grant Nos. 132300410312 and 182102311057), and the 2017 Higher Education Teaching Reform Research and Practice Project of Henan Province (Grant No. 2017SJGLX459).

The study was approved by the Medical Ethics Committee of Second Chinese Medicine Hospital of Zhumadian City, Zhumadian, China) for sampling and using urine and serum.

\section{References}

1 Q. Ma, K. Li, and S. F. Zhang: J. Anal. Sci. 32 (2016) 5. https://doi.org/10.13526/j.issn.1006-6144.2016.05.023

2 C. Y. Liu and C. Gao: J. Instrum. Anal. 31 (2012) 2. https://doi.org/10. 3969/j.issn.1004-4957.2012.02.011

3 C. Y. Lu and Z. H. Wang: J. Instrum. Anal. 31 (2012) 9. https://doi.org/10. 3969/issn.1004-4957.2012.09.017

4 S. J. Li, D. H. Deng, and G. F. Wang: Chin. J. Anal. Lab. 31 (2012) 3. https://doi.org/10.13595/j.cnki.issn10000720.2012 .0066

5 Z. Lin, L. J. Zhu, F. F. Wang, N. M. Wu, and X. H.Lin: J. Instrum. Anal. 34 (2015) 5. https://doi.org/10.3969/j. issn.1004-4957.2015.05.016

6 C. F. Shen, Z. F. Zhang, Y. A. Guo, and Q. G. Yan: J. Instrum. Anal. 35 (2016) 8. https://doi.org/10.3969/.1.issn. 1004-4957.2016.08.004

7 X. M. Guo, Z. H. Wang, and J. F. Xia: J. Instrum. Anal. 31 (2012) 4. https://doi.org/10.3969/ j.issn.1004-4957.2012.04.017

8 L. M. Niu, K. Q. Lian, and L. Ma: Chem. Res. Appl. 27 (2015) 10.

9 Q. Zhao, D. L.Duan, D. Chen, X. Y. Yang, H. P Bai, and J. Q. Wang: J. Kunming Univ. 35 (2013) 3. https://doi. org/10.14091/j.cnki.kmxyxb.2013.03.009

10 R. Li, J. Xiong, W. Q. Zhu, Y. Y. Han, and X. Y. He: J. Anal. Sci. 28 (2012) 3.

11 M. Rajesh, A. Srinivasaan, M. Ramalakshmi, and P. Shakkthivel: Sens. Actuators, B 253 (2017) 12. https://doi. org/org/10.1016/j.snb.2017.06.126

12 Y. Y. Yu, J. X. Wang, R. W. Si, Y. Y, Ch. L. Zhang, and Y. C. Yong: Anal. Chim. Acta 985 (2017) 8. https://doi. org/10.1016/j.aca.2017.06.053

13 L. Y. Jiang, G. W. Nelson, J. Abda, and J. S. Foord: Appl. Mater. Interfaces 25 (2016) 8. https://doi.org/10.1021/ acsami.6b03879

14 A. F. Khan, D. A. C. Brownson, E. P. Randviir, G. C. Smith, and C. E. Banks: Anal. Chem. 65 (2016) 88. https://doi.org/10.1021/acs.analchem.6b02638

15 Z. X. Wang and C.Z. Wang: Chem. Sens. 27 (2007) 4.

16 X. L. Sun, C. Han, and W. Zhao: Chem. Res. Appl. 28 (2016) 1080.

17 Y. H. Li, Z. B. Chen, and H. X. Dong: Chem. Res. Appl. 27 (2015) 8.

18 Y. Fang, Q. Jiang, and Q. Wen: Appl. Chem. Ind. 44 (2015) 6. https://doi.org/10.16581/j.cnki.issn16713206.2015.06.036 
19 Z. Y. Ma, J. Y. Li, and W. Xiang : Chem. Res. Appl. 20 (2008) 12.

20 S. Cosio, A. Pellicanò, and B. Brunettia, and C. A Fuenmayor: Sens. Actuators, B 246 (2017) 7. https://doi. org/10.1016/j.snb.2017.02.104

21 D. L. Deng, F. Deng, and B. B. Tang: J. Hazard Mate 322 (2017) 6. https://doi.org/10.1016/j.jhazmat.2017.03.013

22 S. Q. Chen, F. F. Li, Y. X. Zhong, B. Y. Wu, D. Y. Hu, W. Zheng, and D. Y. Zheng: J. Instrum. Anal. 34 (2015) 9. https://doi.org/10.3969/j.issn.1004-4957.2015.09.015

23 Q. F. Zhang, Y. Wang, and Y. N. Ni: Chem. J. Chinese Univ. 36 (2015) 9. https://doi.org/10.7503/cjcu20150184

24 J. N. Gan, Z. Cai, X. L. He, X. L. Qiu, and W. C. Yue: Chin. J. Anal. Chem. 40 (2012) 12. https://doi. org/10.3724 /SP.J.1096.2012.11429

25 H. Wu, L. Zhang, J. C. Li, H. P. Shen, X. Y. Song, and M. D. Wang: J. Anal. Sci. 33 (2017) 2. https://doi. org/10.13526/j.issn.1006-6144.2017.02.016

26 H. P. Peng, M. L. She, X. Liu, P. Liu, W. Chen, A. L. Liu, and X. H. Liu: J. Electroanal. 22 (2016) 1. https://doi. org/10.13208/j.electrochem.1 50727

27 L. Gu, Y. P. Liu, J. Yan, M. Ke, and M. Zhang: Part B: Chem. Anal. 53 (2017) 2. https://doi.org/10.11973/Ihjyhx201702014

28 S. F. Ding, X. J. Lu, and W. X. Liu: Chin. J. Anal. Lab. 35 (2016) 11. https://doi.org/10.13595 /j.cnki.issn10000720.2016 .281

29 R. T. Liu, S. W. Song, K. Hu, T. Zhang, and Z. T. She: J. Instrum. Anal. 36 (2017) 10. https://doi.org/10.3969/j.issn. 1004-4957.2017.10.013

30 J. F. Fan, Y. Cui, Q. H. Wang, and H. Yang: J. Anal. Sci. 31 (2015) 3. https://doi.org/10.13526/ j.issn.1006-6144.2015.03.015 